\title{
Germ Cell
}

National Cancer Institute

\section{Source}

National Cancer Institute. Germ Cell. NCI Thesaurus. Code C12597.

Gametes, also known as sex cells or germ cells, are the cells that come together during fertilization or conception in organisms that reproduce sexually. Their genetic complement consists of a single set of unpaired chromosomes. 